\title{
Supplementation in the
} Concentrations of Creatine Kinase, Creatinine, Urea and
Lactate on Male Swimmers

\begin{abstract}
Keywords: Supplementation; Creatine; Creatine kinase; Creatinine: Urea

Abstract

The purpose of this study consisted in analyzing the alteration in samples of Creatine Kinase (CK), Creatine and Urea, in male swimmers under creatine supplementation. Seventeen athletes took part in a sequence of tests in a swimming pool $(8 \times 100 \mathrm{~m}$ freestyle $)$ with progressive sets starting at 65 leading up to a $100 \%$ maximum capacity sets. The athletes were evaluated immediately before and after the tests $(5 \mathrm{~min})$, in order to obtain levels of CK. Creatine and Urea concentrations. After 6 days of supplementation with Creatine $(20 \mathrm{~g} /$ day) + maltodextrin $(1 \mathrm{~g} / \mathrm{kg} /$ day $)$ or nothing but maltodextrin control ( $1 \mathrm{~g} / \mathrm{kg} / \mathrm{day})$, new tests similar to the initials, were performed. The variables were analyzed by non-parametric tests of Wilcoxon (in the same group) and Mann-Whitney (between the groups). In statistical terms, a significant level was established: $p<0.05$. On CK it was observed, after supplementation, a statistically significant increase in the Creatine group at rest $(172.83 \mathrm{mg} / \mathrm{ul} \pm 2.43$ to $326.42 \mathrm{mg} / \mathrm{ul} \pm 13.69$ ) and in the end of the tests $(202.32 \mathrm{mg} / \mathrm{ul} \pm 21.85$ to $363.33 \mathrm{mg} / \mathrm{ul} \pm$ 20.53). The same occurred with the creatine concentration at rest (1.05 $\mathrm{mg} / \mathrm{dll} \pm 0.12$ to $1.27 \mathrm{mg} / \mathrm{dl} \pm 0.20)$ and in the end of the tests $(1.23 \mathrm{mg} /$ $\mathrm{dl} \pm 0.23$ to $1.53 \mathrm{mg} / \mathrm{dl} \pm 0.26$ ) with the only tendency of a significant comparison with the control group $(p=0.06)$. Significant differences in urea concentrations were not observed.
\end{abstract}

\section{Introduction}

\section{Creatine and creatine kinase}

Creatine is a nitrogenous amine. A normal diet can provide approximately $1 \mathrm{~g}$ of creatine obtained with the consumption of meat, fish and other products of animal origin. The indication of daily intake to maintain optimum levels of creatine is $2 \mathrm{~g}$. The other needed gram is obtained through an endogenous production of amino acids as glycine, arginine and methionine, from the kidneys, the pancreas and the liver. This occurs through a transaminase reaction that transfers the amino group of arginine to glycine, ornithine and guanidinoacetate. This reaction is reversible with the presence of the transaminase enzyme. Creatine is then formed by the transfer of a methyl group from S-adenosilmationina to guanidinoacetate through a methyltransferase [1].

When creatine is produced by the body or when it is ingested in diet is almost entirely absorbed by the muscles and at that same time the enzyme creatine kinase promotes phosphorylation of creatine. Creatine in the muscle tissue cannot be synthesized, therefore the use, in this case, of a creatine/sodium transporter [2].

Phosphocreatine is formed by the association of muscle creatine

\section{Journal of}

Nutrition and Health

\section{Vinicius Dobgenski, Maria Gisele dos Santos* and Richard Kreider}

Department of Physical Education, Federal University of Paraná, Curitiba - PR, Brazil

\section{*Address for Correspondence}

Maria Gisele dos Santos, Department of Physical Education, Federal University of Paraná, Curitiba - PR, Brazil, E-mail: mariagisele@yahoo.com

\section{Submission: 14 April, 2016}

Accepted: 12 May, 2016

Published: 16 May, 2016

Copyright: () 2016 Dobgenski V. This is an open access article distributed under the Creative Commons Attribution License, which permits unrestricted use, distribution, and reproduction in any medium, provided the original work is properly cited.

with the phosphate group. In a high-intensity activity, intramuscular phosphocreatine and ATP are limited and stocks last around 10 seconds [3]. As with phosphocreatine, the substance turns itself into a cyclic product, creatinine that is excreted in urine about $2 \mathrm{~g} /$ day [4]. Phosphocreatine is directly involved in the formation of Adenosine triphosphate (ATP), and this reaction is catalyzed by Creatine kinase (CK):

$$
\mathrm{PCr}+\mathrm{ADP}+\mathrm{H}+\leftrightarrow \mathrm{ATP}+\mathrm{Cr} .
$$

By muscle biopsy, it is possible to determine that the total average amount of creatine is $124.4 \mathrm{mmol} / \mathrm{kg}$ of dry weight muscle, and of this, $49.0 \mathrm{mmol} / \mathrm{kg}$ is free creatine $(39 \%)$ and $75.4 \mathrm{mmol} / \mathrm{kg}$ phosphocreatine $(61 \%)$. The remaining $5 \%$ of body creatine content are mainly located in the brain and in the heart. This distribution of creatine in the body indicates that it is carried through the bloodstream, from the places of synthesis to the places of use [3].

The total creatine and its derivatives can be increased up to $30 \%$ by supplementation, the mechanism through which creatine supplementation may have potential ergogenic effects consists in an increase of creatine and phosphocreatine in muscle content, which allows an increase in speed resynthesis of ATP, a decrease in muscle fatigue and a better recovery during repeated highintensity exercises [5]. The effects of creatine supplementation have been quite completely studied in sedentary or moderately trained individuals, in laboratory conditions. However, we know very little about their possible influence on well-trained athletes participating in competitions. The athletes who were supplemented with creatine showed better results, especially in sports that require high-intensity activities [6].

Thus, creatine supplementation may be beneficial for high performance athletes, particularly in sports of high intensity, suchin the reduction of muscle fatigue during workouts, allowing the realization of training sessions at higher intensities [7].

\section{Serum urea}

With reference levels between 10-50 mg/dl, serum urea levels are altered by different forms of action on the metabolism. Glucocorticoids and thyroid hormones increase reacting to the decrease of androgens 
Citation: Dobgenski V, Santos MGd, Kreider R. Effects of Creatine Supplementation in the Concentrations of Creatine Kinase, Creatinine, Urea and Lactate on Male Swimmers. J Nutri Health. 2016;2(1): 5.

and growth hormone serum levels. Despite being a marker of renal function, is considered less efficient than creatinine because of different non-renal factors that can affect its concentration. However, it manifests anearlier elevation and does not suffer from any variation of the muscle mass. Differently, the joint assessment with creatinine is useful in the diagnosis about the causes of renal injury. High levels of urea occur during a kidney disease, reduction of the renal blood flow (dehydration, for example), obstruction of the urinary tract and increasing in the protein catabolism (burnings). Decreased levels of urea occur in severe hepatic impairment, malnutrition and superhydration [8].

\section{Methods}

\section{Participants}

Seventeen swimming athletes volunteered took part in this study. The participants were swimming athletes (competitors in master or professional level) from various swimming centers in the city of Curitiba/Pr-Brazil, as well as swimming athletes not associated with the swimming centers. The participants were performing their training for a period of at least five years and were currently attempting to improve their swim speed through a training frequency of at least four days per week. All participants were informed about the procedure and purposes before enrolling in the study and signed an informed consent document that was approved by the Ethics Committee of the Federal University of Paraná, Brazil.

\section{Experimental plan}

A double blind randomization plan was implemented in this study. Participants were required to attend the MobiDick Sport Center three times over a three-week period. During the first visit, the best time achieved by the participants on a 100-meter freestyle swim was recorded and then used as a reference to set the intensity for the two following sessions of exercise. During the next two visits, the participants performed a progressive intensity swim-sprint protocol (see exercise protocol below) in which blood was collected (refer to blood sampling and analysis below) one hour prior to the workout and immediately after the swim-sprint protocol. The first of these visits was conducted without supplementation (T1), and the last testing session (T2) was performed after the ingestion by the participants of creatine plus maltodextrin or just maltodextrin, for a period of six days prior to the workout.

\section{Supplementation}

Participants were divided into two groups: the creatine monohydrate group (CREATINE; $\mathrm{n}=9$ ) was supplemented with $20 \mathrm{~g} /$ day of creatine monohydrate and $1 \mathrm{~g} / \mathrm{kg}$ of bodyweight per day of maltodextrin. The control group (CONTROL; $\mathrm{n}=8$ ) was only supplemented with $1 \mathrm{~g} / \mathrm{kg}$ of body weight per day of maltodextrin. Participants ingested the sports supplements for six days prior to the progressive swim protocol [9]. The supplements, collected in individual bags, one for each day of use, were weighed with a precision balance. Participants ingested the supplements in four equal doses throughout the day; including one of the ingestion 40 minutes prior to the sprint swimming performance. The creatine (Option Corporation ${ }^{\circ}$ ) and maltodextrin (Probiotica ${ }^{\circ}$ ) were acquired from nutritional supplement retail stores in Curitiba-PR.

\section{Exercise protocol}

Data collection was carried out at MobiDick Sport Center located in Curitiba-PR, in swimming pools of 25 meters length. Eight consecutive 100-meter freestyle sets were performed in a progressive intensity format in the following measures [10]:

- 3 sets at $65 \%$ of the best 100 meter time with 3 minutes of rest after each set

- 2 sets at $75 \%$ of the best 100 meter time with 4 minutes of rest after each set

- 1 set at $85 \%$ of the best 100 meter time with 6 minutes of rest after this set

- 1 set at $95 \%$ of the best 100 meter time with 20 minutes of rest after each set

- 1 set at maximum intensity ( $100 \%$ effort)

Percentages of effort were established according to the best time recorded for each athlete, which have been obtained during an initial visit to the MobiDick Sport Center.

\section{Blood sampling and analysis}

All biochemical analyses were performed at the Service of Clinical Analyses from the Federal University Hospital of Parana (SAC/UFPR). Blood samples were obtained through venous collection (needles and syringes) in the antecubital vein of each athlete at two different moments: at rest one hour before the beginning of the progressive swim-sprint protocol and immediately after (within 5 minutes) the swim-sprint protocol. The blood collected was assayed in relation of cortisol, insulin, and blood glucose. Each sample of blood was separated in two tubes: one containing fluoride $(4 \mathrm{ml})$ to determine the presence of glucose and the other containing a gel sifter $(8 \mathrm{ml})$ to analyze the presence of insulin and cortisol. The concentration of circulating glucose was accomplished by the Glucose Hexokinase II method through the Glucose Hexokinase II Kit and ADVIA 1650 reagents (Bayer). Insulin levels were determined by immunoassay and immunometric assay methods on an Immulite 2000 automated analyzer.

\section{Dietary intake}

During the week of the experiment, participants were required to complete a dietary record for three non-consecutive days. Only one of the days could be on a weekend. Participants were instructed to record all food and beverages ingested (including preparation and quantity) as well as time and place in which the food was ingested. In addition, participants were instructed to avoid foods containing caffeine during the week of the experiment due to the concern that caffeine may suppress the effects of creatine [5].

\section{Statistical analysis}

A Shapiro-Wilk test of normality was applied and since the normal condition was not achieved, dependent variables were analyzed by the Wilcoxon non-parametric test. The Mann-Whitney test was used to verify significant differences between the groups. The level of statistical significance was set at $\mathrm{p}<0.05$. Data was analyzed by SPSS 13.0 software for Windows. 
Citation: Dobgenski V, Santos MGd, Kreider R. Effects of Creatine Supplementation in the Concentrations of Creatine Kinase, Creatinine, Urea and Lactate on Male Swimmers. J Nutri Health. 2016;2(1): 5.

ISSN: 2469-4185

Table 1: Characteristics of the athletes taking part in the study.

\begin{tabular}{|c|c|l|}
\hline Athletes & Group Creatine (N-9) & \multicolumn{1}{|c|}{ Group Placebo (N-8) } \\
\hline Age & $25,4 \pm 4,3$ & $23,7 \pm 3,6$ \\
\hline Weight & $81,67 \pm 6,21$ & $78,47 \pm 1,68$ \\
\hline$\%$ Fat & $14,65 \pm 3,95$ & $11,89 \pm 2,21$ \\
\hline Lean Mass & $69,60 \pm 5,24$ & $68,93 \pm 4,92$ \\
\hline Fat Mass & $11,93 \pm 3,64$ & $9,32 \pm 1,77$ \\
\hline Time 100 M (S) & $64,76 \pm 6,48$ & $65,71 \pm 5,74$ \\
\hline
\end{tabular}

*- $\mathrm{P} \leq 0.05$

Table 2: Variation of blood lactate obtained at rest and in progressive effort in percentage.

\begin{tabular}{|c|c|c|c|c|}
\hline \multirow{2}{*}{$\begin{array}{l}\text { Variation of lactate } \\
\text { Rest }\end{array}$} & \multicolumn{2}{|c|}{$\begin{array}{l}\text { Creatine Group } \\
\text { Pre } \\
\text { Post }\end{array}$} & \multicolumn{2}{|c|}{ Placebo Group } \\
\hline & $1,58 \pm 0,64$ & $1,72 \pm 0,76$ & $1,10 \pm 0,47$ & $\begin{array}{l}\text { a } 2,07 \pm \\
0,19\end{array}$ \\
\hline Shot A 65\% & $5,10 \pm 1,61$ & d $4,25 \pm 1,66$ & $4,33 \pm 1,19$ & $\begin{array}{l}\text { a } 5,87 \pm \\
1,54\end{array}$ \\
\hline Shot A 75\% & $8,10 \pm 3.24$ & b $6,43 \pm 1,92$ & $5,80 \pm 1,96$ & $\begin{array}{l}\text { a } 10,40 \pm \\
2,11\end{array}$ \\
\hline Shot A 85\% & $10,22 \pm 2,48$ & ab $7,42 \pm 2,20$ & $9,07 \pm 2,70$ & $11,37 \pm 1,36$ \\
\hline Shot A 95\% & $13,43 \pm 2,88$ & $11,07 \pm 2,13$ & $12,90 \pm 3,60$ & $13,97 \pm 1,73$ \\
\hline Shot A $100 \%$ & $16,68 \pm 3,90$ & $17,17 \pm 4,96$ & $17,10 \pm 4,81$ & $16,27 \pm 2,62$ \\
\hline
\end{tabular}

$P \leq 0.05$ ( $a$ - pre and post on the same group, $b$ - between the groups, $c$ significant trend of the same group, d-significant trend between the groups)

\section{Anthropometry}

The athletes were evaluated with bases on the following aspects: weight, height, circumferences and body composition by Jackson \& Pollock equation [11], seven skinfolds and two circumferences (forearm and abdomen). Circumferences also measured: chest, waist, abdomen, hip, relaxed arm, forearm, upper thigh and calf. This choice was made because it was the most complete formula belonging to the Physical Test 3.4, licensed by the author of the work, and had already been used for several years in some of the athlete's concerned programs.

\section{Laboratory tests}

All biochemical analyses were performed at the Department of Clinical Analysis, Clinical Hospital, Federal University of Paraná (SAC/UFPR), since the determinations of the laboratory procedures were ceded by the biochemists of the hospital.

\section{Results and Discussion}

At the beginning of the study, the two groups (creatine and placebo), did not presentany statistically significant difference related to age, weight, $\%$ fat, lean mass, fat mass and fastest time in $100 \mathrm{~m}$ freestyle (Table 1).

Gain of weight, mostly lean weight due to creatine supplementation, is widely described in the literature and generally attributed to water retention (also due to the short period between measurements - 7 days) $[12,13]$. But, in the placebo group, was found almost the same reduction detected in the creatine group, due to the training period (early season) where athletes were not in their best form yet.

Analyzing statistically blood lactate were observed significant differences within the groups at home and in shots, 65 and $75 \%$ in the placebo group and $85 \%$ in the creatine group (Table 2). However in the placebo group there was an increase of lactate while there was no reduction in the creatine group. The reduction in blood lactate in the group supplemented with creatine was more evident in the percentages of stress 75, 85 and 95\% (Table 3). Indeed, the main reason this reduction occurs is because creatine supplementation promotes a lower degradation of nucleotides and consequently reduces the participation of glycolytic energy production source. The high lactate concentrations may favor the onset of fatigue by increasing the concentration of $\mathrm{H}+$ ions generated by the dissociation of lactic acid to lactate and $\mathrm{H}+$, decreasing the $\mathrm{pH}$. The decreased $\mathrm{pH}$ may be associated with a reduction of the power produced by the inhibition of glycolysis through inhibition of phosphofructokinase enzyme and, consequently, disruption of the energy supply [13].

It is also worth to note that during the tests without reduction in the creatine group the single percentage was $100 \%$. However maximum performance was significantly better in the group that has been supplemented with creatine, certainly generating a higher overall metabolic stress [3].

Statistically significant differences between the groups occurred in the percentages of 75 and $85 \%$, indicating greater effectiveness of the group supplemented with creatine in these intensities and corroborating [14].

Watching the performances in the progressive shots, we did not found any statistically significant difference in the creatine group. $75 \%$ of the swimmers swam above the stipulated time in the post supplementation shot, perhaps reflecting a perception of less effort. The maximum effort in the creatine group, with an average reduction of 1.38 seconds, points to the great effectiveness of creatine supplementation in agreement with several studies [15].

Therefore, it is found that in both groups CK rises during exercise to maintain muscle ATP during the activity, proving that they are indicative of the destruction of muscle cells in response to the great physical stress, which is also reflected by the increase of cortisol. CK

Table 3: Percentages obtained in the time-programmed stress $65,75,85$ and $95 \%$ and a maximum stress free $(100 \%)$.

\begin{tabular}{|c|c|c|c|c|}
\hline \multirow{2}{*}{$\begin{array}{l}\text { Percentage of } \\
\text { Time to } \\
100 \text { M (S) } \\
\text { Shot A } 65 \%\end{array}$} & \multicolumn{2}{|c|}{$\begin{array}{l}\text { Pre } \\
\text { Post }\end{array}$} & \multicolumn{2}{|c|}{$\begin{array}{l}\text { Group } \\
\text { Pre } \\
\text { Post }\end{array}$} \\
\hline & $\begin{array}{l}84,7 \pm \\
10,67\end{array}$ & $81,72 \pm 8,58$ & $\begin{array}{l}87,00 \pm \\
7,21\end{array}$ & $\begin{array}{l}86,43 \pm \\
14,72\end{array}$ \\
\hline Shot A 75\% & $\begin{array}{l}79,38 \pm \\
10,93\end{array}$ & $77,07 \pm 9,80$ & $\begin{array}{l}81,67 \pm \\
7,64\end{array}$ & $\begin{array}{l}80,32 \pm \\
14,98\end{array}$ \\
\hline Shot A 85\% & $\begin{array}{l}72,78 \pm \\
8,86\end{array}$ & $72,82 \pm 8,28$ & $\begin{array}{l}73,33 \pm \\
6,66\end{array}$ & $\begin{array}{l}72,23 \pm \\
12,28\end{array}$ \\
\hline Shot A 95\% & $\begin{array}{l}68,18 \pm \\
7,30\end{array}$ & $66,85 \pm 6,52$ & $\begin{array}{l}69,00 \pm \\
5,29\end{array}$ & $\begin{array}{l}67,36 \pm \\
10,16\end{array}$ \\
\hline Shot A $100 \%$ & $\begin{array}{l}64,76 \pm \\
6,48\end{array}$ & $63,38 \pm 6,52$ & $\begin{array}{l}65,71 \pm \\
6,42\end{array}$ & $\begin{array}{l}65,44 \pm \\
7,81\end{array}$ \\
\hline
\end{tabular}

$\mathrm{P} \leq 0.05$ 
Citation: Dobgenski V, Santos MGd, Kreider R. Effects of Creatine Supplementation in the Concentrations of Creatine Kinase, Creatinine, Urea and Lactate on Male Swimmers. J Nutri Health. 2016;2(1): 5.

ISSN: 2469-4185

Table 4: Values related with Creatine kinase (CK) at rest and at the end of the sequence of tests, before and after the proposed supplementation.

\begin{tabular}{|c|c|c|c|c|}
\hline \multirow{3}{*}{$\begin{array}{c}\text { Biochemical } \\
\text { CK Rest }\end{array}$} & \multicolumn{2}{|c|}{ Creatine Group } & \multicolumn{2}{|c|}{ Placebo Group } \\
\hline & Before & After & Before & After \\
\hline & 172 & $\begin{array}{c}\text { *\# 326,42 } \pm \\
13,69\end{array}$ & $\begin{array}{c}169,67 \pm \\
1,86\end{array}$ & 168 \\
\hline CK Er & $202,32 \pm 21,85$ & $\begin{array}{c}{ }^{*} \# 363,33 \pm \\
20,53\end{array}$ & $\begin{array}{c}195,33 \pm \\
10,81\end{array}$ & $197,22 \pm 12,66$ \\
\hline
\end{tabular}

P $\leq 0.05$ ( $^{*}$ - pre and post on the same group, \# - between the groups, \pm - significant trend of the same group, ${ }^{* *}$ - significant trend between the groups $\mathrm{P}=0.06$ )

Table 5: Values of urea and creatinine at rest and at the end of the progressive shots.

\begin{tabular}{|c|c|c|c|r|}
\hline \multirow{2}{*}{ Bioquimica } & \multicolumn{2}{|c|}{$\begin{array}{c}\text { Group Creatine } \\
\text { Before }\end{array}$} & \multicolumn{2}{|c|}{$\begin{array}{c}\text { Group Placebo } \\
\text { After }\end{array}$} \\
\hline Ureia Rest & $33,33 \pm 2,80$ & $37,67 \pm 9,67$ & $33,67 \pm 2,88$ & $33,00 \pm 2,68$ \\
\hline Ureia End & $34,50 \pm 4,64$ & $36,17 \pm 6,08$ & $35,00 \pm 4,73$ & $34,00 \pm 4,47$ \\
\hline Creatinina Rest & $1,05 \pm 0,12$ & $\begin{array}{c}* * * \\
1,27 \pm\end{array}$ & $1,07 \pm 0,10$ & $1,10 \pm 0,14$ \\
\hline Creatinina End & $1,23 \pm 0,23$ & $\begin{array}{c}* * * \\
1,53 \pm\end{array}$ & $1,27 \pm 0,23$ & $1,30 \pm 0,24$ \\
\hline
\end{tabular}

$\mathrm{P} \leq 0.05\left(^{*}\right.$ - pre and post on the same group, \# - between the groups, \pm- significant trend of the same group, ${ }^{* *}$-significant trend between the groups)

is located in the cell cytoplasm and is released into the circulation when occurs rupture of these cells. Statistically significant differences are seen in the group supplemented with creatine, demonstrating that the elevation is higher than the normal stress of the exercise. In addition to differences within the groups, the creatine-supplemented group showed statistically significant differences between the groups, equally at rest and at the end of the physical tests (Table 4). This is due to CK be the only enzyme that catalyzes the ATP resynthesis reaction, proving that the ATP-CP pathway was exacerbated [15].

SAKS et al. compared the CK activity in different muscles, and showed that the highest activity of this enzyme happens in the muscle that predominates fast type fibers (glycolytic, type II) depending by glycolysis [16]. The total CK activity in this case is approximately 10 times the maximum capacity of ATP consumption. This type of muscle performs an intense and explosive work as energy reserves for immediate use. The continuation of this contraction pattern depends on the capacity of ATP per unit time, as well as an efficient elimination of ADP produced.

No significant differences were observed in urea both between groups and within groups, in disagreement with Oopik et al. work that previously observed an elevation of serum urea in rats supplemented with creatine [17]. Reference values between 10-50 $\mathrm{mg} / \mathrm{dl}$ for urea were not exceeded, despite being observed a nonsignificant increase in the group supplemented with creatine (Table 5). Even though it is a marker of renal function, urea is considered less efficient than creatinine by different non-renal factors that can affect its concentration. However, its elevation is earlier, and does not suffer from the change in muscle mass. The joint assessment with the creatinine is useful in the differential diagnosis of the causes of kidney injury which does not seem to be the case of this sample [18].
In the creatine group were observed significant differences in creatinine, both at rest and at the end of the $100 \mathrm{~m}$ shots. Between the groups were detected statistically significant differences after supplementation in the end of the fitness tests, and a significant trend $(\mathrm{p} \leq 0.06)$ at rest. This can be explained based on the fact that creatinine is a product of degradation of phosphocreatine (RHR) in the muscle, as a result of creatine metabolism. This indicates the increasing content of RHR and a greater use of the ATP-CP system [18].

The reference levels for men range from 0.7 to $1.2 \mathrm{mg} / \mathrm{dL}$ (60-110 $\mathrm{mml} / \mathrm{l})$. However, despite a level of $2.0 \mathrm{mg} / \mathrm{dL}(150 \mathrm{ml} / \mathrm{l})$ may indicate a normal kidney function in a man with large muscle mass. Showing these parameters the athletes are within normal limits.

\section{Conclusions}

Concerning these samples, clarifications in the supplementation area are always very helpful to swimmers that aim to compete. In the specific case of creatine, as we saw in many technical swimmers suffering a reduction in performance because of weight gain caused by the increase of the hydrostatic drag, expending more energy and losing possible gain with the supplementation. In the present study is demonstrated that this concern, the gain of weight overall while increasing performance, is not justified for sprinters.

Blood lactate once again proves to be the best option that can be used to control swimmers' training. The major contribution given to this study, upon this issue, is the percentage of training where the greatest effectiveness of supplementation was between 75 and $85 \%$ of the fastest time. The reduction of lactate still demonstrates the use of lower and higher glycolytic via ATP-CP system, enabling better performances in the 100 meter freestyle. Due to the type of supplemental proposed: high dose of creatine $(20 \mathrm{~g})$ and the short term (6 days), this system can be used with similar gains in pre-competition phase. The possibility of more intense workouts and shorter intervals between shots within the range of $75-85 \%$ at best time can yield improved performances over the medium term. Concluding, we advise future studies with maintenance supplementation (approximately $5 \mathrm{~g}$ /day) for a longer period of training in order to verify these changes.

Analyzing urea and creatinine it was found that the values normally considered as healthy did not exceeded, showing the supplemental security model maintaining a certain regard to renal impairment.

The increased Creatine kinase (CK), in the group supplemented with creatine above the values of the placebo group, demonstrates the increased use of ATP-CP system.

\section{References}

1. Calfee R, Fadale P (2006) Popular ergogenic drugs and supplements in young athletes. Pediatrics 117: e577-e589.

2. Shao A, Hathcock JN (2006) Risk assessment for creatine monohydrate Regul Toxicol Pharmacol 45: 242- 251

3. Balsom PD, Soderlund K, Sjodin B, Ekblom B (1995) Skeletal muscle metabolism during short duration high-intensity exercise: influence of creatine supplementation. Acta Physiol Scand 154: 303-310. 
Citation: Dobgenski V, Santos MGd, Kreider R. Effects of Creatine Supplementation in the Concentrations of Creatine Kinase, Creatinine, Urea and Lactate on Male Swimmers. J Nutri Health. 2016;2(1): 5.

\section{ISSN: 2469-4185}

4. Wilmore $\mathrm{JH}$, Costill $\mathrm{DL}$ (2001) Sport and exercise physiology, $\left(2^{\text {nd }} e d n\right)$. Manole.

5. Vandenberghe K, Gillis N, Van Leeputte M, Van Hecke P, Vanstapel F, et al. (1996) Caffeine counteracts the ergogenic action muscle creatine loading. $J$ Appl Physiol (1985) 80: 452-457.

6. Kreider RB (2003) Species-specific responses to creatine supplementation Am J Physiol Regul Integr Comp Physiol 285: R725-R726.

7. Williams MH, Kreider RB, Branch JD (1999) Creatine: The Power Supplement. Human Kinetics, Champaign, IL, pp. 1-264.

8. Lehninger AL, Nelson DL, Cox MM (2002) Principles of biochemistry, ( $3^{\text {rd }}$ edn) Worth Publishers.

9. Tristscheler K (2003) Measurement and evaluation in physical education and Barrow \& McGee sports: Fifth edition. Manole.

10. Maglischo EW (1999) Nadando ainda mais rápido. Manole.

11. Jackson AS, Pollock ML (2004) Generalized equations for predicting body density of men.1978. Br J Nutr, 91: 161-168.

12. Rawson ES, Volek JS (2003) The effects of creatine supplementation and resistance training on muscle strength and weightlifting performance. J Strength Cond Res 17: 822-831.

13. Kreider RB (2003) Effects of creatine supplementation on performance and training adaptations. Mol Cell Biochem 244: 89-94.

14. Mendes RR, Pires I, Oliveira A, Tirapegui J (2004) Effects of creatine supplementation on the performance and body composition of competitive swimmers. J Nutr Biochem 15: 473-478.

15. Schlattner U, Tokarska-Schlattner M, Walliman T (2006) Mitochondria creatine kinase in human health and disease. Biochim Biophys Acta 1762 $164-180$

16. Saks VA, Ventura-Clapier R, Aliev MK (1996) Metabolic control and metabolic capacity: two aspects of creatine kinase functioning in cells. Biochim Biophys Acta 1274: 81-88.

17. Oopik V, Timpmann S, Medijainen L, Aleksejeva T (1996) Effect of creatine administration on blood urea level and postexercise glycogen repletion in liver and skeletal muscle in rats. Ann Nutr Metab 40: 359-363.

18. Huso ME, Hampl JS, Johnston CS, Swan PD (2002) Creatine supplementation influences substrate utilization at rest. J Appl Physiol (1985) 93: 2018-2022. 